\title{
Percutaneous left ventricular pseudoaneurysm closure
}

Tomas Hnat, Radka Adlova, Jiri Fiedler, Josef Veselka

Department of Cardiology, $2^{\text {nd }}$ Medical School, Charles University, University Hospital Motol and $2^{\text {nd }}$ Medical School, Charles University, Prague, Czech Republic

Submitted: 2 November 2017

Accepted: 27 December 2017

Arch Med Sci 2020; 16 (5): 1247-1249

DOI: https://doi.org/10.5114/aoms.2020.94326

Copyright @ 2020 Termedia \& Banach

Left ventricular pseudoaneurysm (LVPSA) is a rare complication following myocardial infarction, cardiac surgery, infection, and chest trauma, and recently it has also been described as a complication of a transapical access site for cardiac procedures (such as transapical aortic valve replacement [1] or transapical mitral valve procedures). It is caused by a free wall rupture contained by an adherent pericardium, not leading to an immediate hemopericardium and cardiac tamponade. However, the risk of a fatal rupture remains high. Frances et al. [2] reported mortality rates up to $30-45 \%$ when treated conservatively and even though more recent studies $[3,4]$ show better long-term outcome even if LVPSA is left untreated, surgical repair has historically been preferred. Given the fact that many patients undergoing cardiac procedures are at high risk considering surgery or reoperation, percutaneous approaches to closure of LVPSA have recently been described [5]. We present our experience with transfemoral closure of a posterobasal left ventricular pseudoaneurysm using the atrial septal defect (ASD) occluder.

In October 2016, a 70-year-old female patient with infectious mitral valve endocarditis complicated by severe mitral regurgitation due to posterior leaflet perforation and perforation of a paravalvular abscess underwent cardiac surgery consisting of mitral valve replacement using an SJM Epic $25 \mathrm{~mm}$ bioprosthesis and repair of the left ventricle and left atrium using a bovine pericardium. She recovered well and was transferred to a local hospital for subsequent antibiotic treatment. A month after the surgical treatment the patient was admitted to our department with acute worsening of exertional dyspnea and progressive heart failure.

Transesophageal echocardiography revealed $3 / 4$ paravalvular mitral regurgitation and a $36 \times 39 \mathrm{~mm}$ posterobasal left ventricular pseudoaneurysm (Figure $1 \mathrm{~A}$ ) with 2 separate leaks just under the mitral bioprosthesis. Contrast-enhanced computed tomography angiography of the heart confirmed $57 \times 33 \times 35 \mathrm{~mm}$ LVPSA (Figure 1 B) that was deviating the patient's circumflex artery. The diameter of the wider neck of the LVPSA was $7 \mathrm{~mm}$. Coronary catheterization and angiography of the left ventricle (LV) were performed afterwards, revealing a dynamic obstruction of the left marginal artery by the LVPSA. Consequently, a cardiovascular surgeon was consulted and the surgical closure was contraindicated because of high operative mortality rates associated with a need to repeat sternotomy in a patient with frailty syndrome and severe comorbidities. A decision to perform percutaneous closure was made.

The procedure was carried out under general anesthesia. Transthoracic echocardiographic guidance proved to be sufficient and a transesopha-

\author{
Corresponding author: \\ Josef Veselka \\ Department of Cardiology \\ $2^{\text {nd }}$ Medical School \\ Charles University \\ Prague, V úvalu 84 \\ 15000 Prague 5 \\ Czech Republic \\ E-mail: \\ veselka.josef@seznam.cz
}



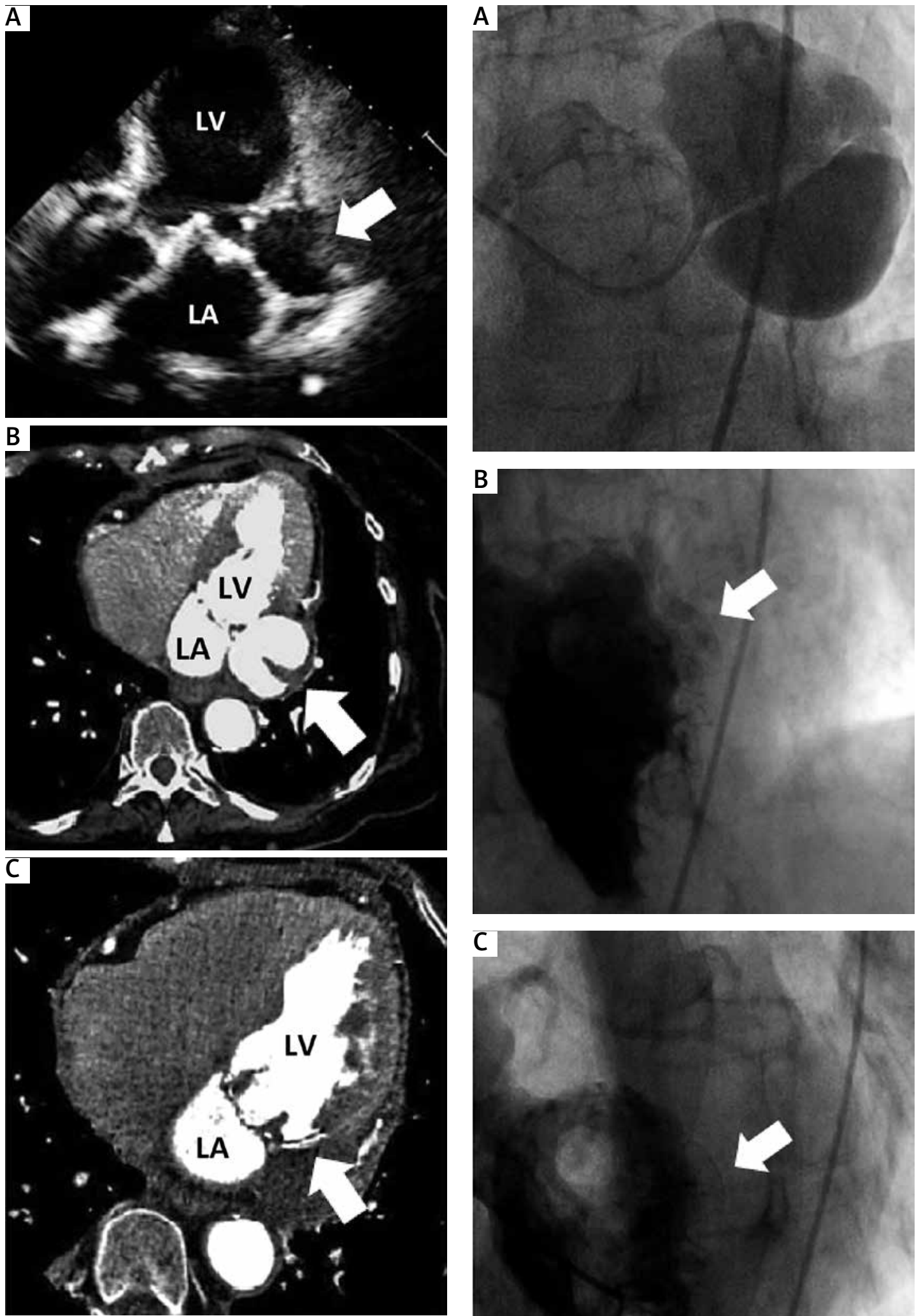

Figure 1. A - Posterobasal left ventricular pseudoaneurysm (arrow) shown in the echocardiographic three chamber apical view. Enhanced computed tomographic angiography showing a left ventricular pseudoaneurysm (arrows) in the transverse view before (B) and 1 month after (C) percutaneous closure using the Occlutech Figulla II ASD Occluder

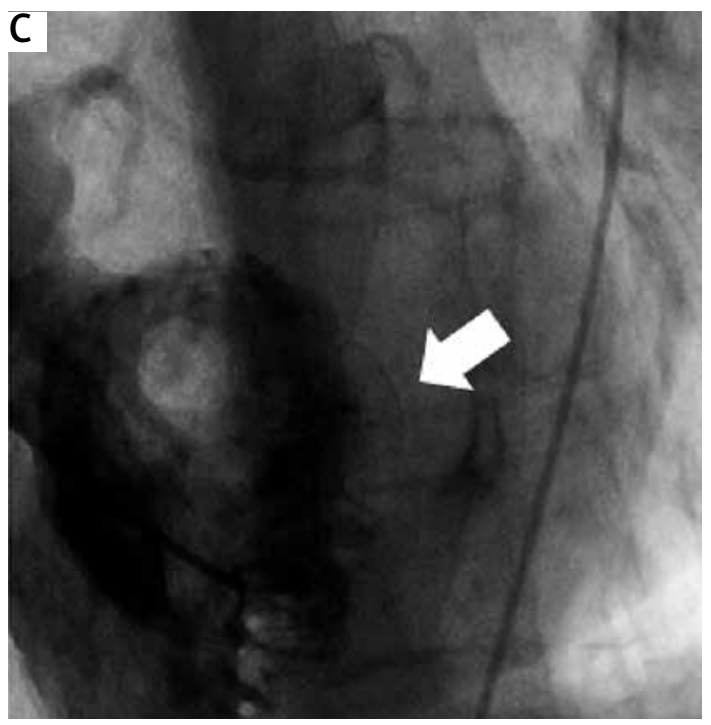

Figure 2. A - Angiography of left ventricular pseudoaneurysm (LVPSA). B, C - Angiography of the left ventricle after percutaneous closure of LVPSA using the Occlutech Figulla II ASD Occluder (arrows)

$L V$ - left ventricle, $L A$ - left atrium. 
geal probe, although available during the whole procedure, was not used. Vascular access was obtained via the left femoral artery using a $14 \mathrm{~F}$ sheath. Angiography of the LV with a pigtail catheter was provided in two projections and a Safari guidewire was then positioned into the LVPSA sac. Via a $95 \mathrm{~cm} 7 \mathrm{~F}$ sheath a $4 \mathrm{~mm}$ Figulla Flex II ASD (Occlutech $\mathrm{GmbH}$, Jena, Germany) device was deployed successfully, but repeated angiography of the LV revealed continuous contrast flow through a neck of the LVPSA. The occluder was removed and exchanged for a $6 \mathrm{~mm}$ Figulla Flex II ASD. Device stability was then verified with a repeated Minnesota maneuver and the positioning prior to release was confirmed using echocardiography. An attempt was made to close the second neck as well, but because of its immediate proximity to the mitral valve bioprosthesis, it was not possible to manipulate a guide wire through the neck into the LVPSA sac. Postimplantation angiography of the LV showed only a negligible flow through the device (Figure 2). The procedure was complicated by access site bleeding with a need of surgical suture of the left femoral artery. Post-procedurally, we decided to provide the patient with no antithrombotic medication. Control angiography of the left ventricle was repeated 5 days and 1 month after the initial procedure - whereas there was still a partial flow through the device as well as through a second communication at 5 days, no flow through the device was observed and a complete exclusion of LVPSA was achieved at 1 month follow-up, which was confirmed by contrast-enhanced computed tomography angiography as well (Figure $1 \mathrm{C}$ ).

Although surgical repair is historically considered to be the treatment of choice in patients with LVPSA, perioperative mortality of such patients remains high [2]. Many patients undergoing cardiac procedures are at high risk. Therefore, for a population of elderly, fragile patients with severe comorbidities, percutaneous closure of the LVPSA seems to be a viable option. Several techniques have been presented. Anatomy, the size and the width of the neck of the LVPSA should be considered when an optimal approach is planned. Left ventricular pseudoaneurysms of a smaller size can be closed using a coil embolisation technique. One must proceed with caution, especially when a wider neck is present, as there is some risk of coil embolisation. Use of a septal occluder, ventricular as well as atrial (Amplatzer, St. Jude Medical, Inc., St. Paul, Minnesota), has also been described [6]. Several different access sites [5] (retrograde - transfemoral, antegrade - transseptal, as well as transapical and direct transthoracic [7]) have been reported, while transfemoral sites have been used the most. Procedures using occluders have had good technical success even if a wide neck is present. The disadvantage of these devices is the possibility of mechanical compression of adjacent epicardial coronary vessels. This report presents our experience with a transfemoral retrograde LVPSA closure using the Figulla Flex II ASD occluder. It demonstrates that even a partial initial closure may successfully lead to a later complete closure after additional endothelization of the device and continuous thrombosis of the LVPSA sac.

In conclusion, percutaneous left ventricle pseudoaneurysm closure using the Figulla Flex II ASD occluder might be a feasible and effective therapeutic approach in patients at high risk for surgical repair. To our knowledge, this is the first report of LVPSA percutaneous closure using this device.

\section{Conflict of interest}

The authors declare no conflict of interest.

\section{References}

1. Karimi A, Beaver TM, Fudge JC Jr. Percutaneous transfemoral closure of a pseudoaneurysm at the left ventricular apical access site for transcatheter aortic valve implantation. J Invasive Cardiol 2015; 27: E27-9.

2. Frances C, Romero A, Grady D. Left ventricular pseudoaneurysm. J Am Coll Cardiol 1998; 32: 557-61.

3. Moreno R, Gordillo E, Zamorano J, et al. Long term outcome of patients with postinfarction left ventricular pseudoaneurysm. Heart 2003; 89: 1144-6.

4. Natarajan MK, Salerno TA, Burke B, et al. Chronic false aneurysms of the left ventricle: management revisited. Can J Cardiol 1994; 10: 927-31.

5. Kumar PV, Alli O, Bjarnason H, Hagler DJ, Sundt TM, Rihal CS. Percutaneous therapeutic approaches to closure of cardiac pseudoaneurysms. Catheter Cardiovasc Interv 2012; 80: 687-99.

6. Kar B, Gholkar G, Gregoric I, Jain S, Loyalka P. Percutaneous closure of a left ventricular pseudoaneurysm in a high-risk surgical candidate. Tex Heart Inst J 2012; 39: 680-2.

7. Moriarty J, Harris TJ, Vorobiof G, Kwon M, Aboulhosn J. Direct percutaneous repair of left ventricular pseudoaneurysm via transthoracic deployment of a ventricular septal defect closure device. Heart Inst J 2015; 42: 362-6. 